\title{
Inflammation and new bone formation: The long lasting debate in axial spondyloarthritis
}

\author{
Tamer A Gheita* \\ Professor of Rheumatology, Faculty of Medicine, Cairo University, Switzerland
}

Received: August 24, 2016; Accepted: August 28, 2016; Published: September 1, 2016

*Corresponding author: Tamer A Gheita, Professor of Rheumatology and Clinical Immunology, Cairo University, Certified European League Against Rheumatism (EULAR) Rheumatologist, Switzerland, E-mail:gheitamer@hotmail.com

\section{Dear Editor}

The complex relation of inflammation to new bone formation in patients with Axial Spondyloarthritis (aSpA) still represents an interesting debate [1]. The two main reasons for this argue focus on having the absence of a good therapeutic efficacy of low or moderate doses of glucocorticoids and Disease Modifying AntiRheumatic Drugs (DMARDs) as the first cause; and secondly, the discrepancy in having a dramatic efficacy of Tumor Necrosis Factor (TNF) blockers in active Ankylosing Spondylitis (AS) patients while not being able to prevent new bone formation in the spine.

As there is more than inflammation in the relation with new bone formation, other key players are involved in the escalation of both processes and form important links or cofactors in this connection. Across the different subtypes of Spondyloarthritis (SpA), the pathophysiology of axial disease may be quite different from that of the peripheral disease. Genetic risk variants of HLAB27, interleukin-23 receptor (IL-23R), IL-1A, IL-12B and other factors suggest a partially distinct genetic background. Moreover, whether axial immunopathology is similar between different SpA subtypes or phases of the disease remains mysterious [2]. In a previous study, IL-23 was significantly higher in Inflammatory Bowel Disease (IBD) patients with peripheral arthritis and/or aSpA [3].

The molecular pathways including Bone Morphogenic Proteins (BMPs), Wnt $[4,5]$, as well as hedgehog proteins that mechanically trigger new bone formation are not yet fully understood. Interestingly, previous bone degradation is not required for the generation of local bone formation [2]. Oxidative stress and lipid peroxidation are accelerated in untreated patients with active AS [6]. Lipid mediators as prostaglandin $\mathrm{E}_{2}$ may support osteoblast differentiation and fosters new bone formation in SpA due to the proinflammatory effect which is reflected by the high responsiveness to NSAIDs [2]. Cartilage degeneration, indicated by cartilage thinning, enhanced chondrocyte apoptosis, and proteoglycan loss, and subchondral bone thinning, promoted by invasion of the subchondral bone plate by a fibrous tissue originating from the bone marrow, are hallmarks of joint remodeling in AS [7]. These various added factors may provide an indirect explanation for this long lasting question about the relationship between inflammation and new bone formation in aSpA.

In view of the argue on the 2 main hypotheses explaining a certain dissociation between inflammation and new bone formation [1], a multistep process has been claimed [8] assuming that all the pathogenetic mechanisms in the development of SpA run on parallel or gently intersecting tracks. The other assumption based on the previous study of Sieper et al. [9] would keep the door open for proving the suggested relation of inflammation and ongoing bone formation.

In view of the reported association of $\mathrm{C}$ - Reactive Protein (CRP) with progressive sacroiliac joint and spinal damage [10,11], it would be important to perform a study detecting the influence of the AS Disease Activity Score (ASDAS), which includes the measurement of the CRP, on radiographic progression of the spine in aSpA patients. Conducting such a study design would help in clarifying the answer to this critical relation. A definite response was presented in the findings of the landmark longitudinal study of Ramiro et al [12] providing a quantified and clear evidence of the relation in AS. Substantiating the value of the ASDAS-CRP score [1] would raise further proposals for adding MRI detected inflammation to the parameters considered in calculating the disease activity. The mention that baseline bony inflammation seen on MRI was the strongest predictor of radiographic spinal progression [13] further confirmed the evidence for such a principal proposition.

More clues to the answer for this question were provided by the results of the milestone prospective study on the Outcome in Ankylosing Spondylitis International Study (OASIS) cohort [12] showing that also the clinical parameters of disease activity correlated with radiographic progression in AS. The reported limitation of relatively long disease duration and lower female frequency in the landmark OASIS forms a demanding suggestion for further studies to consider recruiting patients with earlier stages of the disease with gender adjustment [1].

Solving the mystery of this multifaceted relation would help in accurately deciding the therapeutic potential of the 
available treatment strategies [14] beyond inflammation and new bone formation. There is sufficient evidence presented on the prospective effect of using a TNF blocker for early treatment of aSpA with an obvious retard in radiographic progression, but in long-standing AS a combination with another drug inhibiting new bone formation might be necessary [1]. This editorial strictly focuses on this pivotal causal relation that may help in paving the way for a more specific and potential targeted therapy. Furthermore, a clinical trial investigating the effect of combination therapy of a TNF blocker with an NSAID and possibly also other key players of the pathogenic mechanisms would be of interest.

\section{References}

1. Sieper J, Poddubnyy D. Inflammation, new bone formation and treatment options in axial spondyloarthritis. Ann Rheum Dis. 2014;73:1439-1441.

2. Baeten D, Breban M, Lories R, Schett G, Sieper J. Are spondylarthritides related but distinct conditions or a single disease with a heterogeneous phenotype? Arthritis Rheum. 2013;65(1):12-20.doi: 10.1002/ art.37829.

3. Gheita TA, El Gazzar II, El-Fishawy HS, Aboul-Ezz MA, Kenawy SA. Involvement of IL-23 in enteropathic arthritis patients with inflammatory bowel disease: preliminary results. Clin Rheumatol. 2014;33(5):713-717.doi: 10.1007/s10067-013-2469-y.

4. Uderhardt S, Diarra D, Katzenbeisser J, David JP, Zwerina J, Richards W, et al. Blockade of Dickkopf (DKK)-1 induces fusion of sacroiliac joints. Ann Rheum Dis. 2010;69:592-597.doi:10.1136/ard.2008.102046.

5. Heiland GR, Appel H, Poddubnyy D, Zwerina J, Hueber A, Haibel $\mathrm{H}$, et al. High level of functional dickkopf-1 predicts protection from syndesmophyte formation in patients with ankylosing spondylitis. Ann Rheum Dis. 2012;71(4):572-574:doi.10.1136/ annrheumdis-2011-200216.

6. Ozgocmen S, Sogut S, Ardicoglu O, Fadillioglu E, Pekkutucu I, Akyol O. Serum nitric oxide, catalase, superoxide dismutase, and malondialdehyde status in patients with ankylosing spondylitis. Rheumatol Int. 2004;24(2):80-83.
7. Bleil J, Maier R, Hempfing A, Schlichting U, Appel H, Sieper J et al. Histomorphologic and histomorphometric characteristics of zygapophyseal joint remodeling in ankylosing spondylitis. Arthritis Rheumatol. 2014;66(7):1745-1754.doi:10.1002/art.38404.

8. Lories RJ, Luyten FP, de Vlam K. Progress in spondylarthritis. Mechanisms of new bone formation in spondyloarthritis. Arthritis Res Ther 2009;11(2):221.doi:10.1186/ar2642.

9. Sieper J, Appel H, Braun J, Rudwaleit M. Critical appraisal of assessment of structural damage in ankylosing spondylitis: implications for treatment outcomes. Arthritis Rheum 2008;58(3):649-656.DOI: $10.1002 /$ art.23260

10.Poddubnyy D, Rudwaleit M, Haibel H, Listing J, Märker-Hermann $\mathrm{E}$, Zeidler $\mathrm{H}$ et al. Rates and predictors of radiographic sacroiliitis progression over 2 years in patients with axial spondyloarthritis. Ann Rheum Dis 2011;70(8):1369-1374.doi:10.1136/ard.2010.145995.

11. Poddubnyy D, Haibel H, Listing J, Märker-Hermann E, Zeidler H, Braun $J$ et al. Baseline radiographic damage, elevated acute-phase reactant levels, and cigarette smoking status predict spinal radiographic progression in early axial spondylarthritis. Arthritis Rheum 2012;64(5):1388-1398.doi:10.1002/art.33465.

12. Ramiro S, Van der Heijde D, van Tubergen A, Stolwijk C, Dougados M, van den Bosch F. et al. Higher disease activity leads to more structural damage in the spine in ankylosing spondylitis: 12-year longitudinal data from the OASIS cohort. Ann Rheum Dis 2014;73(8):1455-1461. doi: 10.1136/annrheumdis-2014-205178.

13. Baraliakos X, Heldmann F, Callhoff J, Listing J, Appelboom T, Brandt $\mathrm{J}$ et al. Which spinal lesions are associated with new bone formation in patients with ankylosing spondylitis treated with anti-TNF agents? A long-term observational study using MRI and conventional radiography. Ann Rheum Dis. 2014;73(10):1819-1825.doi: 10.1136/ annrheumdis-2013-203425.

14.Smolen JS, Braun J, Dougados M, Emery P, Fitzgerald O, Helliwell P et al. Treating spondyloarthritis, including ankylosing spondylitis and psoriatic arthritis, to target: recommendations of an international task force. Ann Rheum Dis. 2014;73:6-16.doi:10.1136/ annrheumdis-2013-203419. 